\title{
Diskussion zum Vortrag von M. Pflanz
}

Die Medizin braucht die Soziologie, weil die Gesundheit laut Definition der Weltgesundheitsorganisation auch ein sozialer Begriff ist. Nur eine interdisziplinäre Zusammenarbeit bringt neue Erkenntnisse. - Auf die Frage, wie sich der Mediziner in der Soziologie ausbilden könne, wird geantwortet, daß Spezialkurse und Fortbildungskurse, wie sie zurzeit zum Beispiel in Los Angeles durchgeführt werden, eine gute Lösung darstellen.
Von soziologischer Seite wird die Notwendigkeit der Zusammenarbeit betont, um so mehr als es noch wenig ausgebildetes Personal gibt und soziologische Probleme in verschiedensten Fachgebieten zu lösen wären. In der Medizin eröffnet sich dem Soziologen ein großes und dankbares Betätigungsfeld. Die Zahl der Diplomarbeiten in Medizin-Soziologie nimmt vielerorts zu. 